\title{
Evaluation of the flexural resistance and stress contraction of a silorane-based composite submitted to different protocols of polymerization
}

Murilo Baena Lopes ${ }^{1 *}$, Amanda Daisy Serralvo ${ }^{1}$, Klissia Romero Felizardo², Bruno Shindi Hirata', Ricardo Danil Guiraldo ${ }^{1}$, Sandrine Bittencourt Berger ${ }^{1}$, Alvaro Henrique Borges ${ }^{3}$ and Alcides Gonini Júnior ${ }^{1}$

* Correspondence:

baenalopes@gmail.com

${ }^{1}$ University of North Parana, Rua Marselha, 183, Londrina CEP 86041-100, Paraná, Brasil Full list of author information is available at the end of the article

\begin{abstract}
When introduced to the market, silorane-based materials promised less contraction compared to other materials. The purpose of this study was to evaluate the contraction stress, flexural strength, and elastic modulus of the Filtek Silorane composite with different photoactivation protocols. Filtek Silorane and Filtek Z350 composites were inserted in a circular photoelastic resin matrix and subjected to photoactivation at $650 \mathrm{~mW} \mathrm{~cm}{ }^{2}$ for $40 \mathrm{~s}$ (protocol I), $325 \mathrm{~mW} \mathrm{~cm}$ for $80 \mathrm{~s}$ (protocol II), $100 \mathrm{~mW} \mathrm{~cm} \mathrm{~cm}^{2}$ for $260 \mathrm{~s}$

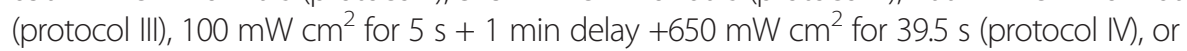

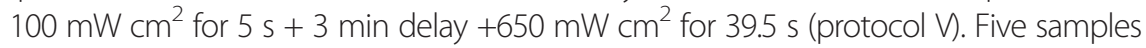
were prepared for each resin with each photoactivation protocol. To determine contraction stress, fringes were analyzed in a polariscope. For flexural strength analyses, 25 specimens $(10 \times 2 \times 2 \mathrm{~mm})$ of each resin with each photoactivation protocol were submitted to the 3 -point bending test in a universal testing machine. Data were submitted to ANOVA and post hoc Tukey's tests $(a=0.05)$. Filtek Silorane showed higher contraction stress results than Filtek Z350 for protocols II (16.4 \pm 3.88 vs. $5.9 \pm 1.64 \mathrm{MPa}), \mathrm{IV}(17 \pm 2.67$ vs. $8.8 \pm 1.30 \mathrm{MPa})$, and V $(16.3 \pm 3.33$ vs. $5.1 \pm 1.95 \mathrm{MPa})$. Both resins showed similar flexural strength values, but the elastic modulus of Filtek Silorane was significantly higher with all photoactivation protocols. Pulse-delay photoactivation was effective for Filtek Z350, but not Filtek Silorane, because the elastic modulus and contraction stress were reduced for Filtek Z350 without any change in flexural strength.
\end{abstract}

Keywords: Composite; Silorane; Shrinkage stress; Photoelasticity; Flexural

\section{Background}

Dental composites still undergo shrinkage during polymerization generating interfacial stress between tooth and restorative material, making researchers continue looking for free-stress materials. This shrinkage, associated with the increase in stiffness of the developing polymer network, generates stresses at the tooth-restoration interface, potentially increasing the risk of premature failure [1]. Shrinkage is related directly to the degree of conversion (DC) of the polymer and, consequently, to the stresses distributed throughout the adhesive interface [2]. Higher DCs contribute to an increased elastic modulus and crosslinking density, which are directly related to stress [3]. The filler also 
influences the magnitude of shrinkage [4] and the elastic modulus [5], thereby contributing to stress development [3].

Recently, some "low-shrinkage" dental composite materials have been developed and marketed. Some of these materials use Bis-GMA as the base monomer, but resort to greater filler loadings or absence of low-molecular weight (MW) diluents to achieve lower shrinkage [6]. Other materials use a prepolymerized resin fillers to reduce the shrinkage. In another approach, high-MW monomers are used, such as methacrylate derivatives of dimer acid. The reduction in polymerization shrinkage is thought to be due not only to the higher MW of the monomer, but also to the formation of a heterogeneous network during polymerization through a polymerization-induced phaseseparation mechanism [6]. Nanosized domain structures are formed at different rates, which allows flow in the viscous phase and accommodates shrinkage within the bulk of the material [1,7]. These conditions reduce the polymerization stress, in spite of the higher DC achieved by this material due to its more chemically reactive components.

Monomers with epoxide ring-opening polymerization-type chemistries, such as silorane-based monomers, have been proposed to provide less shrinkage compared to monomers with free-radical, vinyl polymerization-type chemistries [8]. Silorane-based composites are polymerized via a cationic mechanism that is virtually insensitive to oxygen inhibition. The presence of a siloxane core, to which oxirane rings are attached, makes the molecule fairly hydrophobic [8-10]. The cationic ring-opening polymerization of this epoxy material results in an inherently low volumetric shrinkage compared to vinyl monomer-based materials $[11,12]$. Previous studies showed that silorane-based materials exhibit reduced stress $[13,14]$.

In the present study, the contraction stress was analyzed by photoelastic analysis, in which the internal stresses of a photoelastic material are transformed by visible light to determine the location and magnitude of the stress. Stresses generated on inlays, onlays, crowns, posts, abutments, and implants have been analyzed through photoelastic analysis $[15,16]$. Contraction stress of composite resin is also analysed, however, by means of qualitative method, which may be converted to quantitative using specific equations [17]. This study has used an automatic polariscope, in which the stress can be analysed qualitatively point-by-point, allowing accuracy reading of stress in locations of interest.

Stress during polymerization predominantly occurs due to contraction. The magnitude of the stress depends on the composite's stiffness, ability to relieve stress, flow capacity, and polymerization rate [18], as well as the photoactivation protocol. To minimize contraction stress and shrinkage during polymerization, a "soft-start" photoactivation protocol with a low initial irradiation may be used [19]. In this method, the reaction initiates at a slower rate, thereby slowing development of the elastic modulus, giving the material an opportunity to accommodate the dimensional change of viscosity, and leading to a reduction in the shrinkage stress at the adhesive interface [19]. As a variation of this technique, an interval may be introduced between two pulses (pulse-delay). Polymerization is continued in the dark at lower rates after the initial light pulse and then completed at higher irradiation intensity.

Accordingly, the objective of this study was to evaluate the contraction stress, flexural strength, and elasticity modulus of the silorane-based Filtek Silorane composite through different photoactivation methods. The null hypothesis was that there would 
be a difference in shrinkage stress between the different materials when the different activation protocols were used.

\section{Methods}

Fifty resin photoelastic circular rings $(5.0 \mathrm{~mm}$ in diameter $\times 2.0 \mathrm{~cm}$ in height) were prepared. After resin polymerization, photoelastic silicone matrices were prepared for each photoelastic ring, and the rings were placed inside the matrices. Internal walls of the rings were subjected to air abrasion with $50-\mu \mathrm{m}$ alumina particles, to provide the surface roughness necessary for retention of a composite resin increment. The Scotchbond Multipurpose adhesive system (3 M ESPE) and Silorane adhesive (3 M ESPE) were applied on the air-abraded flat end of the rings. Photoactivation was performed with the VIP halogen light-curing unit (Bisco, Schaumburg, IL, USA) for $20 \mathrm{~s}$, as recommended by the manufacturer.

Samples were polymerized with the VIP halogen light-curing unit, with one of the following five photoactivation protocols (Table 1). Five specimens were prepared for each photoactivation protocol, totaling 25 specimens each for groups 1 and 2.

Four points, diametrically opposed and equidistant from each other, were marked with pencil at $1 \mathrm{~mm}$ of the edge of the restoration on the photoelastic material. Stresses were measured with a polariscope (Vishay LF/Z-2, Malvern, PA, USA), and photographs were taken from each measurement at each point (Figure 1). Data on polymerization shrinkage stress (in $\mathrm{MPa}$ ) were calculated using the software provided with the equipment (PS Calc 2.0).

Flexural strength was evaluated by the 3-point flexural test, in accordance with ISO specification 4049 (2001). Twenty-five rectangular-shaped specimens were obtained from groups 1 and 2. The material was inserted in an acetate matrix, and a strip of transparent polyester was positioned on the top and bottom surfaces. Each side of the matrix was polymerized in accordance with the corresponding photoactivation protocol (I-V), by the VIP halogen light-curing unit. Specimens were removed from the matrix and finished manually under water cooling with 1200-grit SiC paper (Norton SA, São Paulo, SP). Specimens were stored in distilled water at $37^{\circ} \mathrm{C}$ for $24 \mathrm{~h}$, and then the dimensions of each specimen were measured with a digital pachymeter (Mitutoyo, Tokyo, Japan) with a precision of $0.01 \mathrm{~mm}$.

Table 1 Photoactivation protocols

\begin{tabular}{lll}
\hline Protocol & Group 1 (N = 25) & Group 2 (N = 25) \\
& Filtek Z350 & Filtek Silorane \\
\hline I, Continuous high intensity & $650 \mathrm{~mW} / \mathrm{cm}^{2}$ for $40 \mathrm{~s}(\mathrm{n}=5)$ & $650 \mathrm{~mW} / \mathrm{cm}^{2}$ for $40 \mathrm{~s}(\mathrm{n}=5)$ \\
II, Continuous medium intensity & $325 \mathrm{~mW} / \mathrm{cm}^{2}$ for $80 \mathrm{~s}(\mathrm{n}=5)$ & $325 \mathrm{~mW} / \mathrm{cm}^{2}$ for $80 \mathrm{~s}(\mathrm{n}=5)$ \\
III, Continuous low intensity & $100 \mathrm{~mW} / \mathrm{cm}^{2}$ for $260 \mathrm{~s}(\mathrm{n}=5)$ & $100 \mathrm{~mW} / \mathrm{cm}^{2}$ for $260 \mathrm{~s}(\mathrm{n}=5)$ \\
IV, Pulse delay with 1-min interval & $100 \mathrm{~mW} / \mathrm{cm}^{2}$ for $5 \mathrm{~s}+1 \mathrm{~min}$ & $100 \mathrm{~mW} / \mathrm{cm}^{2}$ for $5 \mathrm{~s}+1 \mathrm{~min}$ \\
& interval $+650 \mathrm{~mW} / \mathrm{cm}^{2}$ for & interval $+650 \mathrm{~mW} / \mathrm{cm}^{2}$ for \\
V, Pulse delay with 3-min interval & $39.5 \mathrm{~s}(\mathrm{n}=5)$ & $39.5 \mathrm{~s}(\mathrm{n}=5)$ \\
& $100 \mathrm{~mW} / \mathrm{cm}^{2}$ for $5 \mathrm{~s}+3$ min & $100 \mathrm{~mW} / \mathrm{cm}^{2}$ for $5 \mathrm{~s}+3 \mathrm{~min}$ \\
& interval $+650 \mathrm{~mW} / \mathrm{cm}^{2}$ for & interval $+650 \mathrm{~mW} / \mathrm{cm}^{2}$ for \\
& $39.5 \mathrm{~s}(\mathrm{n}=5)$ & $39.5 \mathrm{~s}(\mathrm{n}=5)$ \\
\hline
\end{tabular}



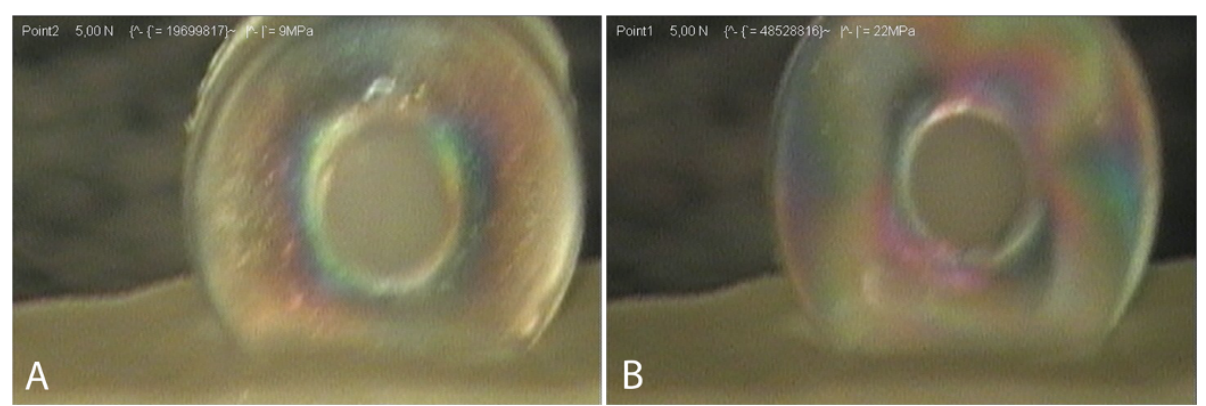

Figure 1 Photoelastic images. Representative images of the Filtek Z-350 (A) and Flltek Silorane (B) specimens captured by the polariscope software after stress analysis. The software registered the value of stress in MPa on the figures.

Flexural strength was determined in a 3-point mechanical testing machine (EMIC DL2000, São José dos Pinhais, PR, Brazil) at a speed of $0.5 \mathrm{~mm} / \mathrm{min}$. Each sample was placed in the device with a distance of $5 \mathrm{~mm}$ between two metallic supports. Flexural strength (FS) was calculated by the formula: $\mathrm{RF}=3 \mathrm{P}_{\mathrm{f}} \mathrm{L} / 2 \mathrm{WH}^{2}$, where $\mathrm{P}_{\mathrm{f}}$ is the maximum load (in $\mathrm{N}$ ) required to fracture the specimen, $\mathrm{L}$ is the distance between the supports $(5 \mathrm{~mm}$ ), and $\mathrm{W}$ and $\mathrm{H}$ are the specimen width and thickness (in $\mathrm{mm}$ ), respectively. Flexural tests were monitored by software on a computer connected to the mechanical testing machine, which generated a "stress $\times$ strain" graph automatically during the test.

The elastic modulus for each specimen, corresponding to the elastic deformation of the material, was calculated from the linear portion of the "tension-deformation" curve. The elastic modulus $(E)$ was calculated by the formula: $E=(\Delta \mathrm{F} / \Delta \mathrm{y}) \times\left(\mathrm{L}^{3} / 4 \mathrm{WH}^{3}\right)$, where $\Delta \mathrm{F} / \Delta \mathrm{y}$ is the change in force $(\Delta \mathrm{F})$ per unit change in deflection of the center of the specimen $(\Delta \mathrm{y}), \mathrm{L}$ is the distance between the supports $(5 \mathrm{~mm})$, and $\mathrm{W}$ and $\mathrm{H}$ are the specimen width and thickness (in $\mathrm{mm}$ ), respectively. Data were submitted to twoway ANOVA and post hoc Tukey's tests at the $5 \%$ significance level.

\section{Results}

Filtek Silorane exhibited higher contraction stresses compared to Filtek Z350 for protocols II (continuous medium-intensity, $16.4 \pm 3.88$ vs. $5.9 \pm 1.64 \mathrm{MPa})$, IV (1-min pulsedelay, $17 \pm 2.67$ vs. $8.8 \pm 1.3 \mathrm{MPa}$ ), and V (3-min pulse-delay, $16.3 \pm 3.33$ vs. $5.1 \pm$ $1.95 \mathrm{MPa}$ ), as shown in Table 2 . Both composites showed statistically similar values of

Table 2 Means and standard deviation of contraction stress (MPa)

\begin{tabular}{lcc}
\hline Photoactivation Protocol & $\begin{array}{l}\text { Group 1 } \\
\text { Filtek Z350 }\end{array}$ & $\begin{array}{c}\text { Group 2 } \\
\text { Filtek Silorane }\end{array}$ \\
\hline I, High continuous intensity & $10.5 \pm 1.27 \mathrm{Aa}$ & $15.1 \pm 1.29 \mathrm{Aab}$ \\
II, Continuous medium intensity & $5.9 \pm 1.64 \mathrm{Aab}$ & $16.4 \pm 3.88 \mathrm{Ba}$ \\
III, Continuous low intensity & $6.9 \pm 1.24 \mathrm{Aab}$ & $11.4 \pm 2.10 \mathrm{Ab}$ \\
IV, Pulse delay with 1-min interval & $8.8 \pm 1.30 \mathrm{Aab}$ & $17.0 \pm 2.67 \mathrm{Ba}$ \\
V, Pulse delay with 3-min interval & $5.1 \pm 1.95 \mathrm{Ab}$ & $16.30 \pm 3.33 \mathrm{Ba}$ \\
\hline
\end{tabular}

Means followed by a different capital letter on the same line or different lowercase letter in the same column are statistically different $(p<0.05)$. 
flexural resistance. However, the elastic modulus values of Filtek Silorane were higher $(\mathrm{p}<0.05)$ with all photoactivation protocols (Table 3$)$.

\section{Discussion}

According to obtained results, the null hypothesis should be accepted because there was no difference between the materials when different polymerization methods were applied. As the speed of the reaction appeared to be decreased for Filtek Z350 but not for Filtek Silorane, we can consider that conventional activation is more suitable than pulse-delay for silorane-based resins.

The polymerization contraction stress does not correspond to the percentage shrinkage value provided by the Archimedes test method because the polymerization shrinkage force includes the inherent elasticity $(E)$ of the composite. The polymerization shrinkage force (in $\mathrm{MPa}$ or $\mathrm{N} / \mathrm{mm}^{2}$ ) can be defined as the product of polymerization shrinkage and the elastic modulus [20]. Using a more elastic composite resin (i.e., with a lower $E$ ) can partially compensate for the polymerization shrinkage and reduce the stresses on the cavity margin. Using a stiffer composite material (i.e., with a higher $E$ ) with identical volumetric/polymerization shrinkage will subject the adhesive bond to greater stress. Any in vitro test is ultimately intended to simulate the clinical situation and should approximate the real clinical demands as closely as possible. Therefore, the polymerization contraction forces actually stressing the cavity margin are much more clinically relevant than the volumetric/polymerization shrinkage [21].

When all of the protocols had the same energy level, the reaction speed of the silorane-based composite was faster than that of the conventional methacrylate. Processing of pre- to post-gel was not influenced by the different protocols. To ensure an effective reduction of stress, a low postgel shrinkage should be closely associated with a relatively low elastic modulus [22]. The pulse-delay method has the ability to prolong the previtrification stage; it decreases the rate of polymerization and, consequently, lowers the stress values, with additional effects on decreasing crosslinking density $[23,24]$. As the polymer forms more quickly, the material spends less time in the pregel or gel phase. This condition leads to stress contraction and, possibly, to greater force dissipation because the material does not have sufficient time to accommodate within the cavity [10]. Using lower irradiance at the beginning of polymerization process can prolong the pre-gel stage, causing the molecules to slide and acquire new positions and orientations slowly, and compensating for the polymerization stress. This mechanism can justify the polymerization stress results of Filtek Z350 when it was photoactivated

Table 3 Flexural strength and elastic modulus

\begin{tabular}{lllllll}
\hline Photoactivation method & \multicolumn{2}{l}{ Flexural strength } & & \multicolumn{2}{l}{ Elastic modulus } & \\
\cline { 2 - 3 } & Filtek Z-350 & Filtek Silorane & & Filtek Z-350 & & Filtek Silorane \\
\hline I, High continuous intensity & $94.9 \pm 7.45 \mathrm{Aa}$ & $117.4 \pm 14.4 \mathrm{Aa}$ & & $5621 \pm 349 \mathrm{Ba}$ & $7852 \pm 653 \mathrm{Aa}$ \\
II, Continuous medium intensity & $94.3 \pm 5.14 \mathrm{Aa}$ & $109.8 \pm 3.76 \mathrm{Aa}$ & & $4505 \pm 543 \mathrm{Bab}$ & $7764 \pm 414 \mathrm{Aa}$ \\
III, Continuous low intensity & $97.5 \pm 17.37 \mathrm{Aa}$ & $116.0 \pm 4.01 \mathrm{Aa}$ & & $5627 \pm 639 \mathrm{Ba}$ & $7651 \pm 325 \mathrm{Aa}$ \\
IV, Pulse delay with 1-min interval & $85.5 \pm 19.16 \mathrm{Aa}$ & $97.9 \pm 6.77 \mathrm{Aa}$ & & $3869 \pm 711 \mathrm{Bb}$ & $6545 \pm 941 \mathrm{Aa}$ \\
V, Pulse delay with 3-min interval & $82.7 \pm 34.4 \mathrm{Aa}$ & $111.4 \pm 9.37 \mathrm{Aa}$ & & $3784 \pm 1206 \mathrm{Bb}$ & $7504 \pm 869 \mathrm{Aa}$ \\
\hline
\end{tabular}

Means followed by different uppercase letter and lowercase letter on the same line and in the same column within the same property are statistically different $(p<0.05)$. 
through the pulse-delay protocols (IV and V); namely, the stress values of Filtek Z350 were high, but they were lower than those obtained with Filtek Silorane. The same mechanisms can justify the Flltek SIlorane results, as its speed of polymerization did not allow a reduction of stress. As the speed of the reaction appeared to be decreased for Filtek Z350 but not for Filtek Silorane, we can consider that conventional activation is more suitable than pulse-delay for silorane-based resins.

In contrast, some authors consider that the stress relief is related to the relaxation of the polymer chains when the vitrification point is achieved [2] or during the conversion of carbon double bonds when high molecular weight molecules are present in all conversion percentages inclusive at lower percentages which are obtained near the end reaction [2]. This condition means that the mobility of the polymer network will be restricted at higher DCs, delaying the gel point and the vitrification point relative to the conversion [25].

Including a greater amount of filler in the matrix reduces the organic content and the material shrinkage [22]. Commercial composites containing a higher percentage of charged particles per volume tend to produce higher stress values. Filtek Z350 contains about $78.5 \%$ filler by weight (63.3\% filler by volume), whereas Filtek Silorane contains $76 \%$ filler by weight (55\% by volume). Kleverlaan and Feilzer (2005) [14] showed that dimethacrylate composites have percentage shrinkages of $2-4 \%$ and stress values of 12-17 MPa, whereas other authors reported stress values of 6-9 MPa, and 8-12.5 MPa [26]. Thus, the material rigidity has a strong influence on the final polymerization tension [27]. As the rigidity is more associated with the crosslink density of the polymeric network than with the full conversion of the reactive species, the elastic modulus may be increased without much effect on the DC [2]. These explanations could help account for the higher elastic modulus values obtained with Filtek Silorane compared to Filtek Z350.

There were no differences in flexural strength between photoactivation protocols or resin composites. One reason for this result is that the Filtek Z350 had high resistance values, similar to Filtek Silorane, despite showing areas with large agglomerations of filler particles related to the morphology and presence of various types of fillers [11]. On the other hand, Filtek Z350 showed lower values of elastic modulus with the pulsedelay protocols. The low elastic modulus was likely responsible for the reduction in shrinkage stress with this resin. Filtek Silorane did not show any difference in the elastic modulus with the pulse-delay protocols, supporting the assumption that there was no time for stress relaxation due to the high speed of the polymerization reaction.

A low elastic modulus is not necessarily associated with high bond strength, but it does result in a more uniform distribution of stresses in the tooth restoration interface, thereby increasing the possibility that adhesion will form with the cavity walls and that the material will resist polymerization shrinkage [28]. Composites with a higher elastic modulus have been associated with greater shrinkage stress because they unable to relieve these stresses through plastic strain during polymerization. Thus, resin composites should have good rigidity (to achieve adequate mechanical properties), but should not be too rigid (to minimize stresses) [29]. Ferracane (2005) [30] indicated that the percentage shrinkage of dental composites is around $1.5-5 \%$, which is sufficient for the development of internal stresses that might endanger the durability of a composite restoration. 
Filtek Z350 contains 8\% (by weight) silica nanoparticles (20-75 $\mathrm{nm}$ in diameter) and $71 \%$ silica/zirconia nanoclusters $(0.6-1.4 \mathrm{~nm}$ in diameter). As it was impossible to observe the smaller particles by SEM, each particle was considered as an aggregate. On the other hand, Filtek Silorane contains quartz particles that cannot be processed by a sol-gel technique, which may explain the more irregular morphology of Silorane compared to other conventional materials [31]. Watts and Al Hindi (1999) [22] reported that compositions with a relatively high content load, as is the case with the studied resins, have significant reductions in shrinkage, following by lower values of shrinkage stress.

\section{Conclusion}

The pulse-delay photoactivation method was more effective for Filtek Z350 compared to Filtek Silorane. The Filtek Z350 resin exhibited reduction of the elastic modulus and contraction stress without changes in the flexural resistance with this photoactivation protocol.

\section{Competing interests}

The authors declare that they have no competing interests.

\section{Authors' contributions}

ADS, AHB, RDG and AGJ participated in performing the experiments. KRF and BSH contributed to the writing of the manuscript. SBB performed the statistical analysis. MBL conceived of the study, participating in its design and coordination, helping to drafting the manuscript. All the authors have read and approved the final manuscript.

\section{Author details}

${ }^{1}$ University of North Parana, Rua Marselha, 183, Londrina CEP 86041-100, Paraná, Brasil. '2Piracicaba Dental School, State University of Campinas, Av. Limeira, 901, Piracicaba CEP 13414-903, São Paulo, Brazil. ${ }^{3}$ Cuiabá University, Avenida Manoel José de Arruda 3.100, Cuiabá CEP 78065-900, Mato Grosso, Brasil.

Received: 1 November 2014 Accepted: 26 November 2014

Published online: 10 December 2014

\section{References}

1. Ferracane $J$, Mitchem JC (2003) Relationship between composite contraction stress and leakage in Class V cavities. Am J Dent 16(4):239-243

2. Calheiros FC, Sadek FT, Braga RR, Cardoso PE (2004) Polymerization contraction stress of low-shrinkage composites and its correlation with microleakage in class V restorations. J Dent 32(5):407-412, doi:10.1016/j.jdent.2004.01.014

3. Condon JR, Ferracane $J \mathrm{~L}$ (2002) Reduced polymerization stress through non-bonded nanofiller particles. Biomaterials 23(18):3807-3815

4. Labella R, Lambrechts P, Van Meerbeek B, Vanherle G (1999) Polymerization shrinkage and elasticity of flowable composites and filled adhesives. Dent Mater 15(2):128-137

5. Condon JR, Ferracane $J L$ (2000) Assessing the effect of composite formulation on polymerization stress. J Am Dent Assoc 131(4):497-503

6. Boaro LC, Goncalves F, Guimaraes TC, Ferracane JL, Versluis A, Braga RR (2010) Polymerization stress, shrinkage and elastic modulus of current low-shrinkage restorative composites. Dent Mater 26(12):1144-1150, doi:S0109-5641(10)00209-5

7. Dewaele M, Truffier-Boutry D, Devaux J, Leloup G (2006) Volume contraction in photocured dental resins: the shrinkage-conversion relationship revisited. Dent Mater 22(4):359-365, doi:10.1016/j.dental.2005.03.014

8. Ilie N, Hickel R (2006) Silorane-based dental composite: behavior and abilities. Dent Mater J 25(3):445-454

9. Boaro LC, Goncalves F, Guimaraes TC, Ferracane JL, Pfeifer CS, Braga RR (2013) Sorption, solubility, shrinkage and mechanical properties of "low-shrinkage" commercial resin composites. Dent Mater 29(4):398-404, doi:10.1016/j. dental.2013.01.006

10. Braga RR, Yamamoto T, Tyler K, Boaro LC, Ferracane JL, Swain MV (2012) A comparative study between crack analysis and a mechanical test for assessing the polymerization stress of restorative composites. Dent Mater 28 (6):632-641, doi:10.1016/j.dental.2012.02.008

11. Palin WM, Fleming GJ, Burke FJ, Marquis PM, Randall RC (2005) The influence of short and medium-term water immersion on the hydrolytic stability of novel low-shrink dental composites. Dent Mater 21(9):852-863, doi:10.1016/j.dental.2005.01.004

12. Bausch JR, de Lange K, Davidson CL, Peters A, de Gee AJ (1982) Clinical significance of polymerization shrinkage of composite resins. J Prosthet Dent 48(1):59-67

13. Weinmann W, Thalacker C, Guggenberger R (2005) Siloranes in dental composites. Dent Mater 21(1):68-74, doi:S0109-5641(04)00174-5 
14. Kleverlaan CJ, Feilzer AJ (2005) Polymerization shrinkage and contraction stress of dental resin composites. Dent Mater 21(12):1150-1157, doi: 10.1016/j.dental.2005.02.004

15. Stansbury JW (2000) Curing dental resins and composites by photopolymerization. J Esthet Dent 12(6):300-308

16. Ernst CP, Meyer GR, Klocker K, Willershausen B (2004) Determination of polymerization shrinkage stress by means of a photoelastic investigation. Dent Mater 20(4):313-321

17. Lopes MB, Costa LA, Consani S, Gonini AJ, Sinhoreti MA (2009) SEM evaluation of marginal sealing on composite restorations using different photoactivation and composite insertion methods. Indian J Dent Res 20(4):394-399, doi:10.4103/0970-9290.59428

18. Papadogiannis D, Tolidis K, Lakes R, Papadogiannis Y (2011) Viscoelastic properties of low-shrinking composite resins compared to packable composite resins. Dent Mater J 30(3):350-357

19. Braga RR, Ballester RY, Ferracane $J \mathrm{~L}$ (2005) Factors involved in the development of polymerization shrinkage stress in resin-composites: a systematic review. Dent Mater 21(10):962-970, doi: 10.1016/j.dental.2005.04.018

20. Ernst CP, Kurschner R, Rippin G, Willershausen B (2000) Stress reduction in resin-based composites cured with a two-step light-curing unit. Am J Dent 13(2):69-72

21. Rullmann I, Schattenberg A, Marx M, Willershausen B, Ernst CP (2012) Photoelastic determination of polymerization shrinkage stress in low-shrinkage resin composites. Schweiz Monatsschr Zahnmed 122(4):294-299

22. Watts DC, al Hindi A (1999) Intrinsic 'soft-start' polymerisation shrinkage-kinetics in an acrylate-based resin-composite. Dent Mater 15(1):39-45

23. Carvalho RM, Pereira JC, Yoshiyama M, Pashley DH (1996) A review of polymerization contraction: the influence of stress development versus stress relief. Oper Dent 21(1):17-24

24. Daronch M, Rueggeberg FA, Moss L, de Goes MF (2006) Clinically relevant issues related to preheating composites. J Esthet Restor Dent 18(6):340-350, discussion 351. doi:10.1111/j.1708-8240.2006.00046.x

25. Mondelli RF, Prakki A, Cilli R, Navarro MF, Mondelli J (2003) Surface roughness average and scanning electron microscopic observations of resin luting agents. J Appl Oral Sci 11(4):327-331

26. Moraes RR, Garcia JW, Barros MD, Lewis SH, Pfeifer CS, Liu J, Stansbury JW (2011) Control of polymerization shrinkage and stress in nanogel-modified monomer and composite materials. Dent Mater 27(6):509-519, doi:10.1016/j.dental.2011.01.006

27. Sellinger A, Tamaki R, Laine RM, Ueno K, Tanabe H, Williams E, Jabbour GE (2005) Heck coupling of haloaromatics with octavinylsilsesquioxane: solution processable nanocomposites for application in electroluminescent devices. Chem Commun (Camb) 29:3700-3702, doi:10.1039/b505048k

28. Leprince J, Palin WM, Mullier T, Devaux J, Vreven J, Leloup G (2010) Investigating filler morphology and mechanical properties of new low-shrinkage resin composite types. J Oral Rehabil 37(5):364-376, doi:10.1111/j.1365-2842.2010.02066x

29. Suh BI (1999) Controlling and understanding the polymerization shrinkage-induced stresses in light-cured composites Compend Contin Educ Dent Suppl 25:S34-S41

30. Ferracane JL (2005) Developing a more complete understanding of stresses produced in dental composites during polymerization. Dent Mater 21(1):36-42, doi:S0109-5641(04)00171-X

31. Lu H, Stansbury JW, Dickens SH, Eichmiller FC, Bowman CN (2004) Probing the origins and control of shrinkage stress in dental resin-composites: I. Shrinkage stress characterization technique. J Mater Sci Mater Med 15 (10):1097-1103, doi:10.1023/B:JMSM.0000046391.07274.e6

doi:10.1186/s40563-014-0023-z

Cite this article as: Lopes et al.: Evaluation of the flexural resistance and stress contraction of a silorane-based composite submitted to different protocols of polymerization. Applied Adhesion Science 2014 2:23.

\section{Submit your manuscript to a SpringerOpen ${ }^{\circ}$} journal and benefit from:

- Convenient online submission

- Rigorous peer review

- Immediate publication on acceptance

- Open access: articles freely available online

- High visibility within the field

- Retaining the copyright to your article

Submit your next manuscript at $>$ springeropen.com 